\title{
Устойчивые сравнения в языке спортивного дискурса: русско-украинские параллели*
}

\author{
А. В. САВЧЕНКО \\ Department of Slavic Languages and Literatures, National Chengchi University, No. 64, Sec. 2, \\ 116 Zhinan Road, Wenshan District, TW-11605 Taipei City \\ E-mail: savchenko75@mail.ru
}

(Received: 31 January 2019; accepted: 2 June 2019)

Благодаря тому, что устойчивые сравнения (УС) можно использовать применительно практически к любой сфере жизнедеятельности человека, а сами сравнения могут нести в себе различный заряд экспрессивности, строиться на различных метафорических основах и выполнять различные прагматические функции, они широко используются в языковом обиходе: в письменной и устной речи. Не исключением является и сфера спорта (т. е. спортивный дискурс): вариант языка, обслуживающий данную сферу, где УС выполняют различные прагматические и контекстообразующие функции (об этом подробнее см. САВчЕНКо 2015).

Вслед за И. В. Кузнецовой, под УС в данной статье мы понимаем выражения с компаративным союзом, «в состав которого входят основание сравнения, союз и компаративная часть, обладающее всеми признаками фразеологизма, т. е. это образное, воспроизводимое, употребительное (хотя бы в одной социальной или возрастной группе людей), экспрессивное, устойчивое в семантическом, формально-структурном и функциональном планах сочетание слов с совокупным сигнификативным значением, конструктивным центром которого является компаративный союз, а основой - образы-эталоны» (КУЗНЕЦОВА 2017: 18).

В спортивной сфере УС довольно широко используются как в жанре устного репортажа - комментаторами, спортсменами, тренерами, так и спортивными журналистами в печатных СМИ. В последнее время подобные УС встречаются в языке интернет-СМИ и на различных спортивных форумах, где обсуждение ведут не только спортивные журналисты, но, в первую очередь, сами болельщики.

По своему происхождению УС, которые используются в «языке спорта», можно с достаточной степенью условности разделить на несколько групп:

* Работа выполнена при финансовой поддержке Российского фонда фундаментальных исследований. Проект «Проведение комплексного социолингвистического исследования роли и функций русского языка в украинском полиязычном пространстве и описание положения русского языка в современной языковой ситуации на Украине» (№ 18-012-00754). 
a) УС общего фразеологического фонда языка, которые также используются и применительно к сфере спорта, в том числе трансформированные (по модели или значению); б) УС-профессионализмы - специфические обороты речи спортсменов, как правило жаргонного характера; в) УС-окказионализмы и неологизмы - выражения, созданные самими комментаторами или журналистами и из окказиональных ставшие (достаточно) употребительными. Некоторые такие окказиональные УС могут стать расхожими выражениями и на какое-то время войти в языковой обиход (как правило, однако, лишь в сфере спорта). Достаточно употребительными УС, пришедшими из общего фразеофонда, в языке спортивной журналистики являются такие выражения, как, например: (пройти) как нож сквозь масло; как холодный душ; как чертик из табакерки; (выложить мяч) как на блюдечке; (разыграть) как по нотам и др. Некоторые такие УС сохраняют свое основное значение, которое легко «вписывается» в спортивный контекст и придает ему нужное стилистикопрагматическое значение.

Одним из наиболее расхожих и широкоупотребительных в спортивном дискурсе оказывается УС (разыграть/разыгрывать) как по нотам. Вероятно, такой его популярности способствует и сходство образной внутренней формы: и оригинальная музыкальная сфера, откуда пришло данное выражение, и сфера спорта связаны общим характером основного для них действия - глаголом играть, который объединяет в себе значения и контексты «играть на музыкальном инструменте» и «играть в (спортивную) игру». «Большой словарь русских народных сравнений» дает следующую дефиницию: разыгрывать/paзыграть что как по нотам 'о чем-л. исполненном четко, без затруднений, по заранее подготовленному плану' (БСРНС 2008: 443). В спортивных контекстах рассматриваемое УС используется преимущественно применительно к командным видам спорта (в первую очередь, - это футбол, а также хоккей, баскетбол и др.), где подчеркивается слаженность коллективных действий, например: «Прекрасная трехходовка, разыгранная нашими футболистами, как по нотам, увенчалась точным ударом низом Евгения Щеголева» (ФК «Факел» Воронеж); «[волейболисты] Принимали [подачу] без ошибок - это они умеют все, разыгрывали - как по нотам и отыгрывали все» (Советский спорт, 20.04.2014). ${ }^{1}$ Данное УС употребляется и при описании четких, заученных действий одного спортсмена, например, теннисиста: «Гейм на подаче Лендла разыгрывался как по нотам» (tenis.in.ua, 22.01.2013). Аналогичное УС - як по нотах - встречаем также и в украинском языке: «Але на останній хвилині хлопці розіграли, як по нотах, показову комбінацію» (sport.ua, 08.09.2008). Есть вариант данного УС и с другим сравнительным союзом - немов: «Першу небезпечну комбінацію кияни розіграли немов по нотах» (www.ua-football.com, 10.02.2018).

\footnotetext{
1 Здесь и далее приведены примеры, зафиксированные во время теле- и интернет-трансляций спортивных соревнований, из печатных и интернет-СМИ. Конкретные источники и даты фиксации приводятся в скобках после каждого примера.
} 
Другим расхожим УС, достаточно часто использующимся в языке спортивного дискурса, является выражение как холодный душ или словно холодный душ. Значение данного УС находим в БСРНС: действовать/nодействовать на кого как холодный душ 'о неожиданном и неприятном, отрезвляющем сообщении, наставлении, сюрпризе' (БСРНС 2008: 185). Описывая какие-л. спортивные события, журналисты (иногда и сами спортсмены) используют данное УС в двух основных контекстах: 1) 'о неожиданно пропущенном голе (в футболе, хоккее)': «На „Тосно“ пропущенный гол подействовал как холодный душ на сонного человека, запахло жареным, и гости понеслись в атаку» (moi-portal.ru, 15.04.2015); «Пропущенная шайба подействовала на ярославцев как холодный души, и они заметно активизируются» (redstar.ru, 10.04.2003); «Ангарчан пропущенная шайба заставляет взбодриться, словно холодный душ» (НТС, 02.03.2015); 2) 'о поражении (как правило, неожиданном)': «Поражение словно холодный душ, наконец, отрезвило летающих в облаках японок. Разозленные не на шутку бронзовые призеры Тайбея в третьей партии показали кто есть кто в женском волейболе, и уверенно победили со счетом в четвертой партии 25:13» (deafsportnews.ru, 03.08.2011). В сочетании с глаголом остудить - остудить как холодный душ - УС часто употребляется в значении 'подавить сопротивление соперника': «Марк Дэвис, словно холодный душ, остудил пыл еще одного китайца Ляна Вэньбо своими брейками в 57, 88, 55, 51 и 71 очко» (snooker.by, 31.01.2014). В украинском языке подобное УС используется не так широко, как в русском, в том числе и применительно к сфере спорта. Примечателен, однако, такой фрагмент высказывания А. Михайличенко, некогда тренировавшего футбольную сборную Украины: «Настав час прийняти холодний дуи. Сподіваюся, він освіжить наші голови, і до осінніх ігор ми підійдемо в найкращому стані» (www.epochtimes. com.ua, 19.08.2009).

Следующим весьма расхожим и широкоупотребительным УС в сфере спорта является выражение как на блюдечке [с голубой каемочкой], имеющее словарную дефиницию: шутл.-ирон. 'о чем-л., что подается кому-л. в готовом виде, без каких-л. усилий, труда с его стороны’ (БСРНС 2008: 52).

Выражение используется, в основном, применительно к игровым играм спорта с мячом или шайбой, в первую очередь, в описании футбольных и хоккейных матчей, где данное УС, как правило, употребляется в значении 'сделать удобную передачу, удобный пас' и чаще всего используется в сочетании с глаголом выложить - выложить (мяч, передачу) как на блюдечке: «Какая атака! Яролим выложил мяч как на блюдечке Штайнеру, который должен был забивать третий мяч, но снова Ковалевски сыграл восхитительно!» (soccer.ru, 10.10.2009); «Гавлат выцарапал шайбу у Роя, укрыл шайбу от Ференса и выложил ее как на блюдечке Элиашу, которого перед матчем чествовали за 1000-й результативный балл в НХЛ» (sports.ru, 11.02.2015). В украинском языке встречаем аналогичное УС - як на блюдечку: «Юліан Дракслер накрутив двох захисників, увійшов у штрафний майданчик і видав як на блюдечку м’яч форварду „Бешикташа“” (www.ukrinform.ua, 26.06.2016). 
Максимально близким по образу данному УС и одинаковым по значению в русском и украинском языке является вариант рус. как на тарелочке - укр. як на тарілочиі: «Лемиш, как на тарелочке, выложил мяч Воронину, удар у которого с 30 метров получился на загляденье: мяч вонзился в „девятку“» (Спорт-Экспресс, 30.07.1996) - «Він такі паси видає на 40-50 метрів, як на тарілочиіi» (sport.ua, 09.09.2018).

Примечательно, что некоторые УС уже нашли отражение в словарях. Так, в «Большом словаре русских народных сравнений» УС как нож в масло зафиксировано именно в своем «спортивном» значении, причем в качестве основного (первого): ходить/войти (вреза́ться/вре́заться) куда как нож в масло - прост. 1. 'о легко и точно попавшем в ворота футбольном мяче, легко забитом голе'. Второе значение, приводимое в указанном словаре, тоже вполне соотносимо со сферой спорта: 2. 'о легком, естественном и свободном проникновении чего-л. (при ударе, попадании и т. п.)' (БСРНС 2008: 441). Именно второе значение данного УС - о легком и свободном прохождении обороны, свободном проникновении игрока (или мяча) в нужное ему место на поле - наиболее характерно для него при описании спортивных состязаний: «,Трехи“ летели через сопротивление, диагонали и проникающие передачи вниз после неудачных сдваиваний соперника проходили, как нож сквозь масло» (sports.ru, 03.08.2010).

По нашим наблюдениям, чаще всего рассматриваемое УС встречается в контекстах, когда описывается именно легкость проникновения игроков через оборону соперника (в командных видах спорта): «В матче с рижским „Динамо“ финский легионер „Трактора“ подобрал шайбу в своей зоне и прорвался через оборону соперника, как нож в масло, поставив точку в своем сольном проходе хорошим броском с неудобной руки» (Чемпионат.ру, 04.10. 2011); «Сначала капитан турков Шанли, как нож в масло прошел оборону и [...] отправил первый мяч в ворота украинцев» (gazeta.ua, 13.08.2009). Наиболее частотный вариант - (пройти) как нож сквозь масло. Вместо предлога в здесь используется предлог сквозь, дополнительно подчеркивающий совершенный (т. е. завершенный) характер действия: «Хакансон как нож сквозь масло прошел оборону [баскетбольной] сборной России. Не разобрались защитники кому именно держать шведа» (Советский спорт, 07.09.2013); «Русские осаждали защиту Оранье, и атаки согласно футбольному выражению проходили „как нож сквозь масло“ и были типичной чертой игры русских» (hollandomania.ru).

Яркая метафорическая образность данного УС позволяет использовать его в разных контекстах, где оно может приобретать дополнительные оттенки значения и выполнять различные прагматические задачи. В этой связи интересно употребление данного УС в контекстуальном значении 'легко справиться с соперниками; легко выиграть поединок у своих противников’: «Однако Джонса, который прошелся через „шеренгу убийц“ полутяжелого веса, как нож сквозь масло, лишили титула» (Спорт-Экспресс, 24.05.2015); «Другие потенциальные конкуренты - Энди Роддик и Рафаэль Надаль - выбыли на 
ранних стадиях. А без них главный фаворит прошел через турнирную сетку как нож сквозь масло» (Известия, 13.08.2005), «Прославленный американский теннисист Энди Роддик [...] в завершающем матче дня как нож сквозь масло прошел непростого австралийца Бернарда Томича» (e-mail.ru, 01.09.2012).

Иногда в речи комментаторов, спортсменов и языке спортивных журналистов и болельщиков встречаются и другие варианты рассматриваемого УС, в частности: словно нож в масло; словно нож через масло; словно нож масло; как нож через масло; как нож масло...

В украинском языке рассматриваемое УС также встречается в нескольких вариантах, в зависимости от сравнительного союза как в функции сравнения: як / наче /мов ніж крізь масло и в основном используется в контексте с глаголом движения пройти/проходити: «А вже в другій половині гри героєм поєдинку став Олег Шокун, який проходив через захисні редути хустського колективу наче ніж крізь масло й записав на свій рахунок покер» (fcmunkach.com, 14.10.2018); «Бабенко пройшов повз захисників, як ніж крізь масло, і чітко підсік м'яч над ногою Сорокіна» (cherkassy-sport.com, 26.11. 2012); «А потім Крихов'як, мов ніж крізь масло, проскочив через опорну зону мерсисайдців і підключив одинокого Гіббза - про Родрігеса забули і він оформив дубль» (football24.ua, 27.01.2018).

В упомянутый словарь русских устойчивых сравнений в спортивном значении вошло УС как из пушки: жарг. спорт. 'об очень сильном ударе в футбольной игре’ (БСРНС 2008: 554). Подобный образ заложен и в украинское УС немов з гармати: «Рікардінью не думав здаватися і видав черговий блискучий гол, красиво обігравши Андресіто і немов з гармати вистріливши під поперечину» (korrespondent.net, 09.02.2016). Отметим и то, что в языке спортивного дискурса (в речи спортсменов, комментаторов и болельщиков) основной компонент данного УС пушка употребляется в значении 'мощный удар по мячу' (НикитинА-РОГАЛЕВА 2010: 198).

Говоря об УС общего фонда в спортивных контекстах, нельзя не вспомнить и УС как чертик из табакерки, которое также нередко употребляется в языке спортивного дискурса в своем основном значении: ум. прост. ирон. 'о чьем-л. неожиданном и быстром появлении где-л.' (БСРНС 2008: 746): «Аршавин, как чертик из табакерки, может появиться где угодно» (Еврофутбол, 09.10.2009). Однако основное значение может претерпевать контекстуальные трансформации значения, в частности в примере: «Немцы, приглашенные на турнир не за боевые заслуги, а по протекции НХЛ, выскочат на Кубке мира, словно чертик из табакерки» (Советский спорт, 21.08.2004). Это УС уже имеет значение 'неожиданно для остальных участников соревнований превратиться в основного фаворита'. Аналогичное УС, использующееся в спортивных контекстах, обнаруживаем и в украинском языке: «Після невдалої скидки воротареві когось 3 футболістів „Десни“ [...] і навісу відрапорця у виконанні Вайди, на ближній штанзі як чортик з табакерки вистрибнув Зайчук» (www.ua-football.com, 31.05.2014); «[Адам Лаллана] в будьякий момент готовий вистрибнути, як чортик з табакерки, щоб засмутити 
суперника» (footballua.tv, 30.12.2016); «Протягом матчу він міг залишатися непомітним і начебто злегка вальяжним, таким чином усипляючи суперників, проте в потрібний момент вискочити, немов чортик з табакерки, і оглушити голкіпера суперників влучним ударом» (footballua.tv, 31.03.2016).

Применительно к футболу весьма частотным можно считать УС (ynacmb) как подкошенный 'о внезапном и непроизвольном падении кого-л. всем телом’ (БСРНС 2008: 514): «Я не ударил Тарасова, не цеплял его, хотел лишь помочь судье разобраться в моменте. Но игрок „Локомотива“ упал как подкошенный» (Чемпионат.ру, 08.04.2015). Или в украинском языке: «Португалець впав як підкошений, випрошуючи для суперника червону картку» (www. obozrevatel.com, 20.06.2018); «Та що ти - не торкався я Фещука! Той артист 3 власної ініціативи впав мов підкошений на газон» (www.ua-football.com, 24.11.2009); «Тренер з кікбоксінгу: Я вже бачив Віталія Кличка на настилі рингу - він впав як підкошений» (заголовок; news.meta.ua, 08.09.2009).

Целый ряд УС возник непосредственно в самой спортивной сфере: в речи комментаторов, спортсменов, спортивных журналистов. Например, в языке спортивной журналистики широкоупотребительными УС (особенно в устных репортажах) стали выражения обыграть как стоячего и (игра) как на качелях. УС обыграть как стоячего используется применительно к командным видам спорта (в первую очередь, применительно к футболу) в значении 'обыграть очень легко, фактически без сопротивления со стороны соперника': «После детской ошибки Акселя Витселя мяч попал к главному забивале „Ливерпуля“ Суаресу. Он без проблем, как стоячего, обыграл [...] центрального защитника Нету и, выйдя один на один с Малафеевым, пробил в дальний угол на точность - мимо» (АиФ, 14.02.2013).

УС (игра) как на качелях благодаря широкому употреблению в последние годы в чисто спортивных контекстах приобрело еще одно дополнительное - спортивное - значение: 'о нервной по своему характеру игре, в которой соперники попеременно имеют преимущество; об игре, результат которой трудно предсказать до самого ее окончания': «Ничего так, игра сложилась в целом, неплохо, победили в овертайме 7:6. Сегодня игра была как на качелях, то мы поведем, то они, в общем, смогли забить на последних минутах овертайма и победили» (sports.kz, 25.02.2010).

При сравнении со значениями, приводимыми в БСРНС: 1. 'о ритмичном, мерно раскачивающемся, колеблющемся движении, качке (обычно в каком-л. движущемся транспорте)'; 2. 'о неравномерных жизненных перепадах, о периодически меняющихся обстоятельствах’ (БСРНС 2008: 251), можно констатировать появление нового («спортивного») значения у данного УС, связанного с описанием конкретного, специфического характера игры, когда итоговый результат абсолютно невозможно предсказать вплоть до самого ее окончания. Этот же образ качелей положен и в основу достаточно употребительного, включая живую разговорную речь, оборота в украинском языке, в том числе и в виде УС: «Гра йшла як на гойдалках - то одна команда виходила вперед, то інша» (beachsoccer.org.ua, 28.08.2017). 
Аналогичный процесс появления дополнительной коннотации произошел с УС как (словно) проходной двор: прост. неодобр. 'о месте, где постоянно и беспрепятственно собираются, толпятся, шумят люди (мешая кому-л. сосредоточиться на чем-л.)' (БСРНС 2008: 161) или неодобр. 'место, организация, куда можно свободно войти и выйти (вступить и уйти)' (ФЕдоРОВ 2008: 174). В спортивном значении это выражение используется для характеристики очень ненадежной обороны в командных видах спорта, об обороне, которую легко переигрывают игроки команды соперника: «Без Рамоса защита „Реала“ словно проходной двор» (footballhd.ru, 08.02.2015). Заметим, что чаще всего это выражение используется не как УС, а как ФЕ проходной двор. Этот же образ заложен и в основу тождественного по значению украинского УС прохідний двір, причем как правило с опущением синтаксического сравнительного компонента - союза як/наче/мов: «„Шахтар“ в результаті виявився найслабшою командою в нашій групі. [...] Центр їх оборони - ие прохідний двір» (sportanalytic.com, 27.11.2018); «Правий фланг захисту „Волині““ другий матч поспіль перетворюється на прохідний двір» (www.volyn. com.ua, 24.04.2014).

Среди спортивных УС встречаются профессиональные (жаргонные), разговорные выражения спортсменов, например, как во дворе (играть). По образности данное УС, вероятно, семантически связано с ФЕ дворовый футбол, т. е. непрофессиональный, некачественный, любительский - в том смысле, что профессионалы играют как любители во дворе, на очень низком техническом, исполнительском, зрелищном уровне. Как УС, так и ФЕ в контексте имеют стилистический характер неодобрительности, иронии (часто с оттенком сарказма): «Вышедшие футболисты плохо действовали сегодня. Люди играют в футбол, как во дворе» (Прессбол, 31.07.2011).

К жаргонным УС можно отнести выражения срать (навалить) как полковая лошадь. На языке футболистов это весьма экспрессивное выражение, имеющее иронично-неодобрительный характер, означает 'плохо играть в обороне, допускать большое количество грубых ошибок’: «Защита в первом тайме срала как полковая лошадь, первый гол тупо сами отдали мяч перед воротами, второй не отсчитал защитник [...]: мячик через него перескочил и [...] 2:0» (Футбольный Петербург, 02.06.2008).

В футбольном обиходе также нередко можно услышать шутливое УС выйти как сосиска [вареная] 'неуверенно начать игру': «Свежов, ты будешь играть? Вышел, как сосиска вареная!» (НТВ-Спорт, 27.04.2012).

Широко используются в спортивных контекстах и некоторые хорошо известные УС, по своему происхождению являющиеся жаргонизмами. Так, в частности, о крупной, безоговорочной победе над соперником говорят (noрвать) как тузик грелку, т. е. 'выиграть у кого-л. с большим преимуществом'; «Словарь футбольного болельщика» Т. Г. Никитиной и Е. И. Рогалевой фиксирует еще и вариант расправиться как Тузик с грелкой (НикитинА-РоГАЛЕВА 2010: 249). Приведем один пример, примечательный тем, что в нем упоминается аналогичное УС в украинском языке: «На Украине есть поговорка: 
Порвав як мавпа газету. Так обычно говорят в случае победы любимой команды» (Проза.ру, 03.02.2015); фиксации русскоязычного варианта этого УС(порвать) как обезьяна газету - встречается значительно реже. В основе подобных разговорных экспрессивных выражений, как правило, заложены весьма необычные образы, благодаря своей неординарности (нередко и абсурдности) создающие необходимый эмоционально-выразительный заряд (в частности, как в приведенных примерах пары: тузик-грелка, обезьяна-газета).

Исследовательский интерес также представляют трансформированные и авторские УС сферы спорта. Интересная метаморфоза произошла с выражением гол как сокол. В последнее время оно все чаще встречается в «спортивном» значении: 'о забитом командой красивом голе (преимущественно в футболе, но также и в хоккее)'. Именно в спортивном контексте данное УС уже зафиксировано словарем: 2. жарг. мол. спорт. шутл.-одобр. 'о красивом голе, забитом издалека' < соко́л 'гладкое чугунное орудие, таран в виде ствола, которым раньше пробивали крепостные стены' (БСРНС 2008: 639). Возможно, даваемое авторами словаря уточнение о том, что гол забит издалека, относится не ко всем контекстуальным употреблениям данного УС: часто имеется в виду любой красиво забитый гол. Дискуссионным представляется и мнение о том, что в основе анализируемого УС сохраняется метафорический образ исходного УС. Представляется все же, что в данном случае можно рассматривать это как «метафорическую омонимию»: краткая форма прилагательного в оригинальном УС обыгрывается уже как существительное гол, а также меняется значение слова сокол: во-первых, это возможно за счет переноса ударения: соко́л - со́кол, во-вторых, даже оставляя ударение без изменений, в образном сознании всплывет, скорее, именно аналогия с птицей - соколом, имеющей положительные коннотации; ср. в этом же словаре: со́ко́л *взлетать/взлететь как со́кол-нар.-поэт. высок. 1. 'о молодом и удалом человеке, красиво и ловко вскочившем на коня'; 2 . 'о человеке, быстро и честно добившемся высоких почестей, высокого положения в обществе' (БСРНС 2008: 638), таким образом, происходит замещение исходного метафорического образа другим, омонимичным, имеющего позитивные коннотации.

Устойчивые сравнения представляют из себя весьма благодатную основу для создания новых УС. При этом некоторые авторские окказиональные УС становятся распространенными выражениями и входят в разговорный обиход. Так, например, в речи футбольных комментаторов одним из излюбленных УС стало выражение [пронестись] как электричка мимо нищего в шутливо-ироничном значении: 'очень быстро обогнать соперника; о большом преимуществе в скорости одного игрока над другим'. Выражение вошло в активный обиход спортивной сферы и журналистики и вышло за рамки узко-профессионального жаргонизма благодаря бывшему футболисту, вратарю и спортивному комментатору В. Маслаченко. Приведем в качестве примера один из его комментариев в телеэфире: «Шевченко пронесся мимо защитников „Реала“ как электричка мимо нищего». Сами футболисты часто шутливо называют быстро бегающего игрока электричка. 
Подобные окказиональные авторские УС как правило имеют высокий экспрессивно-эмоциональный потенциал за счет необычности, часто парадоксальности, но в то же время, узнаваемости образа. В качестве иллюстрации приведем лишь один пример: «Было жаль еще совсем недавно задорную и крепкую белорусскую команду, которую в четвертьфинале размазали по льду, как масло по бутерброду. И мелькнула тревожная мысль - не стать бы нам на этом бутерброде знаменитой русской икрой» (Советский спорт, 14.05.2015). В украинском разговорном дискурсе, а также и в интернет-коммуникации встречается более экспрессивное УС [розмазати] як гамно по полю, например, в таком контексте: «Металіст розмазали як гамно по полю» (www.ua-football.com, 24.02.2011).

Часто для создания УС в спортивном контексте можно создать ассоциативную параллель с другими видами спорта: «Здоровенный Серхио Рико не дотянулся до мяча, заброшенного в угол словно рукой» (Советский спорт, 28.05.2015). УС как (словно) рукой употребляется применительно к футболу в значении 'очень точно и аккуратно' по аналогии с играми в мяч руками (баскетбол, гандбол). Или в украинском: «,динамівець“ зі штрафного поклав круглого до сітки, мов рукою» (football24.ua, 18.08.2013). Аналогично в основе метафорической модели может использоваться характерный для определенного вида спорта атрибут: с помощью выражения (сыграл ногой) как клюшкой удачные действия футболиста перед воротами соперника метафорически сравниваются с аналогичными и привычными действиями хоккеиста.

Таким образом, сфера спорта является весьма активной как с точки зрения использования различных УС, уже существующих в языке, так и с точки зрения создания новых УС (т. е. придания новых значений уже существующим УС). УС могут создаваться спонтанно в рамках спортивного репортажа или в тексте статьи, с другой стороны, используя жаргонно-разговорные выражения спортсменов, спортивная журналистика приоткрывает завесу «спортивной языковой кухни», давая возможность зрителям и читателям самим стать частью спортивного дискурса.

Можно отметить, что язык современной украинской спортивной журналистики (включая жанр устного репортажа) является наглядной иллюстрацией межславянской языковой конвергенции, когда схожесть лексики и отдельных фразеологических моделей, метафорических образов, синтаксических конструкций - с одной стороны, и генетическая близость двух восточнославянских языков - с другой, способствуют тому, что русский язык выполняет роль образца для создания устойчивых выражений (журналистских штампов, новых фразеологических единиц, в частности - УС) и «полуофициальных» разговорных терминов, необходимых в журналистике для «оживления» текста, придания ему различных стилистических и прагматических эффектов, увеличения степени экспрессии, воссоздания «атмосферы аутентичности» происходящего во время спортивного состязания.

В то же время, язык современной российской спортивной журналистики в известной степени является сегодня примером для развития украиноязыч- 
ного спортивного дискурса. Речь идет не о терминологии (которая в украинском языке существует и используется давно), а, в первую очередь, о свойственных для языка журналистики - особенно в сфере спорта, где языковая экспрессия максимально востребована в силу самого характера спортивного дискурса, для которого свойственна повышенная эмоциональность, зрелищность - и необходимых для нее ярких экспрессивных оборотах, включая некоторые рассмотренные здесь устойчивые сравнения.

Вероятно, в будущем следует ожидать пополнения количества статей (вокабул) словарей устойчивых сравнений русского и украинского языков и расширения их содержания путем включения в них остающихся пока незафиксированными «спортивных» УС и УС, уже включенных в состав таких словарей, но получивших за счет новых - спортивных - коннотаций новые прагматические значения. Перспективным нам видится и создание двуязычных русско-украинского и украинско-русского словарей устойчивых сравнений, а также спортивной лексики и фразеологии обоих языков.

\section{Литература}

БСРНС 2008 = МокиЕНКО В. М., НикитинА Т. Г. Большой словарь русских народных сравнений. Москва: «ОЛМА Медиа Групп», 2008.

КУЗНЕЦОВА 2017 = КУЗНЕЦОВА И. В. Персонажи Библии в славянских устойчивых сравнениях. Чебоксары: ЧГПУ, 2017.

НикИТИНА-РОГАЛЕВА $2010=$ НикИТИНА Т. Г., РОГАЛЕВА Е. И. Словарь футбольного болельщика. Оле-оле-оле-оле! Москва: «ОЛМА Медиа Групп», 2010.

САВЧЕНКо 2015 = САВченко А. В. «Спортивная фразеология» современного русского языка: общая характеристика и основные особенности. Мир русского слова 2015/4: 31-37.

ФЕДОРОв 2008 = ФЕдОРОВ А. И. Фразеологический словарь русского литературного языка. Москва: «Астрель», «АСТ», 2008.

ALEKSANDR ViKTOROVICH SAVCHENKO

National Chengchi University, Department of Slavic Languages and Literatures

(Taipei, Taiwan)

\section{Stable Comparisons in the Language of Sports Discourse: Russian-Ukrainian Parallels}

Nowadays, sports play an important role in the world, both from the pure competitive (even emulative) and political point of view. The influence of sports is also traced here at the linguistic level: many words and expressions from the field of sports penetrate the language but, on the other hand, the sphere of sports itself becomes a fertile ground for the emergence of new expressive words and idioms having different stylistic and expressive colours that can perform various pragmatic functions. In the language of sports, lexical units often acquire a new meaning related to sports; in some cases, the meanings of already existing metaphorical phraseological models are actualized. 
The paper is devoted to the problem of the status and description of one of the types of phraseological units, i.e. stable comparisons, which are used in the sphere of sports or sports discourse in modern Russian and Ukrainian languages. On the one hand, these units have their origins in sports slang as well as in mass media language and also come from common phraseology and other discourses. On the other hand, such units have not only a high expressive level but they are often used as picturesque and metaphorical means in other discourses, e.g. political, social, or economic. Such expressions are nowadays very popular and commonly used both in spoken language (speech) and in mass media language.

Stable comparisons are, in fact, a universally figurative and expressive means of language which can be used in any situation, context, and in any pragmatic field of language use. The sphere of sports is not an exception, where such language units fulfil various functions both in the language of sports journalism (oral reportages, articles on sports, internet communication and discussions in internet forums specializing in sports) and in the speech of the athletes themselves. This paper discusses some of the most commonly used stable comparisons in the sphere of sports (i.e. sports discourse) both in Russian and Ukrainian languages. The metaphorical models of such units are examined from the point of view of Russian-Ukrainian language convergence. It can be stated that the language of modern Russian sports journalism can be seen today to a certain extent as a possible (or potential) prototype for the development of Ukrainian-language sports discourse.

Generally speaking, live contacts in interdiscourse sports communication, including the language of sports journalism, however, are still ongoing and active language interaction at the level of vocabulary and phraseology remains one of the most effective means of enriching the vocabulary of the national language.

Keywords: the Russian language, the Ukrainian language, sports discourse, mass media, phraseology, idioms, phraseological units, stable comparisons, Slavic languages, Russian-Ukrainian language convergence 